\title{
Coping Strategies of Decision-Making Difficulties and Psychological Resilience of the Gifted in Secondary School
}

\author{
Elballah A. Khaled \\ Department of Special Education, College of Education, King Faisal University, Saudi Arabia
}

Received October 9, 2020; Revised December 21, 2020; Accepted January 20, 2021

\section{Cite This Paper in the following Citation Styles}

(a): [1] Elballah A. Khaled, "Coping Strategies of Decision-Making Difficulties and Psychological Resilience of the Gifted in Secondary School," Universal Journal of Educational Research, Vol. 9, No. 1, pp. 67 - 75, 2021. DOI: 10.13189/ujer.2021.090108.

(b): Elballah A. Khaled (2021). Coping Strategies of Decision-Making Difficulties and Psychological Resilience of the Gifted in Secondary School. Universal Journal of Educational Research, 9(1), 67 - 75. DOI: 10.13189/ujer.2021.090108.

Copyright $\bigcirc 2021$ by authors, all rights reserved. Authors agree that this article remains permanently open access under the terms of the Creative Commons Attribution License 4.0 International License

\begin{abstract}
Interests, abilities, and values may play central roles in the career decision-making of gifted adolescents, so an examination of the career decisions is very important. This research aims to examine the relationship between coping strategies of difficulties in decision-making, the decision-making difficulties, and psychological resilience of the gifted, and determine the differences between male and female in these variables. The total participants in this study were 80 students from secondary school who responded to the coping strategies of difficulties in career decision-making scale, and the decision making difficulties scale, and the psychological resilience scale for the gifted by the researcher. This study used the Pearson's correlation to determine the relationship between the variables, and T.test to determine the differences according to the gender. The results showed that there is statistically significant correlation between coping strategies of difficulties in career decision-making, and decision making difficulties $(\mathrm{r}=0.631)$, and psychological resilience $(\mathrm{r}=0.679)$. addition, there are significant differences in coping strategies of career decision-making in the depending on others, withdrawal, and indecisiveness in favor of females, and in vigilance, impulsiveness, and procrastination in favor of males. There are significant differences in psychological resilience in favor of males in this study. Based on the finding of this study it can contribute to the improvement of the secondary school counselling programs about positive career decision-making strategies.
\end{abstract}

In summary, the findings suggest that high level of psychological resilience can contribute to coping career decision-making difficulties, such as impulsiveness, and procrastination, especially with gifted adolescents.

Keywords Coping Strategies, Resilience, Career, Decision-Making, Gifted, Secondary School

\section{Introduction}

Despite of the numerous psychological areas that have been investigated decision- making; only few studies have examined the relationship between coping strategies of decision-making difficulties, career decision-making difficulties and psychological resilience in gifted adolescents. The expansion of power standards, globalization, and rapid technological progress have In resulted a lack of stable employment opportunities. With modern world's jobs, self-development has become crucial for employment access, thus increasing the challenges faced by students at higher levels in the career decision-making process. The career decision-making difficulties have become an increasing cause of the academic success difficulties, maladjustment, and personal stress. Therefore, individuals need to enhance their coping strategies, and increase psychological resilience and self-determination toward those difficulties, which are 
caused by the individual's characteristics, psychological and cognitive structures, or by external factors such as social and technological changes.

Although these difficulties are faced by young people in general, they are more prominent in the gifted as a group with mental and psychological specificity. Appropriate career decision-making at the secondary level reduces the consequences of gap year after the transition from high school to university. During this period, depending on their professional choices related to the study's type and nature, students realize whether they are studying in the right or in the wrong direction.

The career selection process for gifted can be more than just a step in the process of completing secondary school. It can be a highly personal process that may lead to a deep level of introspection requiring targeted support from the adults in their lives, including teachers, parents, and counselors [10].

Despite of high mental abilities of gifted, they face several obstacles and challenges in discovering and planning their careers, and therefore, require considerable guidance from the school counselors. The assumption exists gifted individuals can make important career decisions for themselves due to their high functioning and overall intelligence. Many researchers found that these students possess a high caliber and knowledge that equips them to cope with life's various demands. However, such myths and perceptions are often falsified. The literature demonstrated that gifted individuals undergo a unique constellation of issues regarding social, emotional, and vocational development, that need to be addressed within the schools and communities [1].

The findings of previous studies (e.g. [11], [23].) showed that procrastination as a strategy was related to the three decision difficulties: lack of readiness, lack of information, and inconsistent information. These results indicated the importance of decreasing procrastination at all stages of career decision-making and the need to promote psychological resilience to deal with decision-making difficulties [23]. The psychological resilience is an interactive phenomenon, which indicates that some individuals achieve good outcomes despite adversity, and this is important for determining risk factors in individuals, especially in situations. Psychological resilience could result from repeated exposure to adversity. Although adversity is the developmental criterion of psychological resilience, human beings have the capacity to adapt to adversity, as an inherent component of personality, and they can acquire the skills and resources when they face adversity. Therefore, we learn from life-long experiences and foster effective coping strategies [4].

\subsection{Statement of the Problem}

Gifted adolescents address developmental challenges specific to them similar to their peers. These challenges include dealing with the problems related to puberty and identity formation, self-esteem needs, career choices, developing friendships, self-awareness, and emotional problems were the most problems they face and decision-making difficulties, due to their high capabilities and multiple interests. Common beliefs regarding career decision-making revolve around standard achievements, aptitudes, interests, and personality assessments that guide students towards sound career decisions. However, as they progress through their career decision-making process, interpersonal conflicts may occur especially when their career aspirations conflict with their personal or family values. When gifted rural adolescents are encouraged by their teachers, school counselors, and parents to leave their homes to pursue their college and career dreams elsewhere, this conflict intensifies. In doing so, these adults inadvertently contribute to the emotional struggle provoked by the important developmental task of adolescence [22].

It is necessary to identify the reasons for indecisiveness and to assess the difficulties that people may face in their attempt to choose a profession. In general, there is a difference between indecisiveness in career choice and chronic indecisiveness; the former refers to a standard stage of decision-making, while the latter refers to the inability to make decisions. The diagnosis of the causes of occupational indecisiveness is an important for the good guidance of individuals [11]. Six positive coping strategies that facilitate professional coping are: useful information seeking, emotional information seeking (reflects efforts to reduce uncertainty regarding the career decision-making), systematic problem solving, flexible decision-making, and, willingness to compromise, adaptability, and self-regulation. There are three supporting strategies: seeking help, seeking emotional support, and delegating responsibility. The unproductive coping style consists of five strategies that hinder coping with career decision-making: escape, helplessness, isolation, submission, and opposition, with a focus on the negative features of career decision-making [13]. The academically gifted students ranked scientist or doctor as their top choices, and occupations such as teacher, sales position, nurse, artist, and actor were less preferred. In comparison to the children with average academic skills, they rated lawyer as their top, nurse, actor, and manager. A study by Chen \& Toyce [2] supported that the general consensus that gifted students generally choose careers considered highly prestigious in status.

Although it is important to investigate the impact of coping strategies of career decision-making difficulties on career decision-making difficulties and psychological resilience, there is a lack of previous studies. The present study focuses on the relationship between coping strategies of career decision-making difficulties, career decision-making difficulties, and psychological resilience, 
as one of the characteristics of positive personality among gifted adolescents. Based on above, this research attempts to answer the following questions:

1. Is there correlation between coping strategies of career decision-making difficulties, career decision-making difficulties, and psychological resilience?

2. Are there differences between males and females in coping strategies of career decision-making difficulties, and psychological resilience?

\subsection{The Significance of the Research}

The theoretical and practical importance of the current research is determined as follows:

A- Theoretical importance:

1. Few of studies focused on coping strategies of career decision-making difficulties among the gifted and its relationship with psychological resilience.

2. The current research interested in the adolescence stage of the gifted, as it is the stage of decision-making and career choice among many alternatives.

3. The research deals with a problem that has psychological and social effects on the gifted, which are important variables that require providing scientific theoretical frameworks, and previous studies that dealt with variables of career decision-making difficulties, and the psychological resilience of the gifted.

B- Practical importance:

1. Prepare of coping strategies difficulties in career decision-making scale, and psychological resilience scale for the gifted, as the Arab library lacks such tools.

2. Make the parents and teachers to be attention to the importance of coping strategies with difficulties of career decision-making among the gifted, and their application at home and school.

3. Make the educators to be attention when preparing academic curricula to emphasize the value of decision-making and its importance in the lives of individuals and training on them in the school context.

\subsection{Research Objectives}

The current research aims to:

1. Verify the existence of a correlation between coping strategies of difficulties in career decision-making, difficulties in career decision-making, and psychological resilience.

2. Identify the direction of the differences between males and females in coping strategies of difficulties in career decision-making and psychological resilience.

\subsection{Definitions of the Main Concepts}

Coping strategies of decision-making difficulties: strategies for coping the decision-making difficulties of young people in professional life differ in one way or another. Some are dominated by anxiety and tension, and some resort to avoidance, withdrawal and dependence on others, and others rely on positive strategies such as: planning, taking the appropriate decision, searching for information and support, and these Positive confrontation is evidence of the individual's enjoyment of health, compatibility and psychological quality of life [12]. The coping strategies, whether positive, problem-based, or negative, emotional-based, represent the group of psychological efforts and processes that the individual employs in managing stress and reducing its negative effects. It is procedurally defined as a set of positive or negative styles that the individual follows in the form of cognitive, behavioral, or emotional steps to reach the decision-making that achieves his goals".

Career decision-making difficulties: Decision-making means the sum of cognitive and behavioral signals to make a choice or preference between many situations, and decision-making difficulties represent the set of obstacle that prevent the individual from making the right decision, such as: delay and procrastination, hesitation, dependence on others Excessive caution, perfectionism, external control, poor self-confidence, lack of responsibility [5]. It is procedurally defined as "the set of difficulties resulting from the lack of available information, the predominance of negative beliefs over the individual, and the reluctance to take a position, which supports internal conflicts and lack of motivation to take action on career options".

Psychological Resilience: means good compatibility and positive confrontation of psychological pressures in light of the individual's personal competence, spiritual values, and social support. It also means "the ability of individuals to face adversity, through their efficiency in strengthening their psychological, social, cultural, and physical resources and methods up to the quality of life or well-being" [20]. It is procedurally defined as "the ability of the individual to achieve personal and social competence, self-acceptance, novelty seeking, positive future orientation, spiritual competence.

Gifted students in the Gulf and Middle East are normally identified by the following criteria: (1) high ability (meaning high intelligence), (2) high creativity, (3) high task commitment, and (4) behavioral characteristics. However, Jordan, Bahrain, and Egypt have added a fifth criterion for identifying gifted students, i.e., having specific academic achievement (e.g., in mathematics) [3]. It is procedurally defined as gifted students at the secondary level who were diagnosed according to the 
criteria for diagnosing giftedness in the Kingdom of Saudi Arabia, which determined by the National Center for Assessment.

\section{Literature Review}

\subsection{Coping Strategies of Career Decision-Making Difficulties}

Confrontation strategies often depend on two dimensions: a helpless and impulsive, axis, such as escape, withdrawal and wishful thinking, apathy and negativity, extreme care, postponement and hesitation, lack of confidence, and dependence on others; and a positive mind-based axis such as seeking information, solving problems, seeking support from specialists, persuasion of the nature of the profession, and rational choice. Heritage focuses on individual differences in skills and resources when using coping strategies, and the importance of understanding how people avoid or stop so many pressures. The analysis of the processes that people use to cope with stress and take actions to prevent or protect against its impact (positive confrontation) going through five phases (realignment of resources, awareness of stress, initial assessment, initial response efforts, and the use of feedback in estimating initial efforts). Some previous studies [12]; [16]; [2] focused on coping strategies that work on two main dimensions: reducing the risk or damage from a stressful event (problem-based strategies) and containing negative emotional reactions (strategy-based). The first pattern is divided into active confrontation and excessive planning; the second pattern has four factors: denial of the problem's existence, self-control that cannot take a path away from emotions, number and means less attention to the responsibility for the situation, positive reassessment and awareness of changes.

Another perspective on coping strategies relies on social support, which provided by Lazar as a common dimension in many coping strategies. It is clear from the heritage that life satisfaction is positively associated with the use of coping strategies and the search for social support; it is also associated with self-esteem and decision-making methods. In addition, there is significant relationships between confrontation and pressure, and decision-making methods [19]. Coping is an individual's cognitive and behavioural effort to face the internal and external demands in stressful situations. Strategies to tackle young people's decision-making difficulties in professional life vary. Some strategies are controlled by anxiety and stress; others resort to avoidance, and withdrawal, or dependence on others, and others rely on positive strategies such as planning, appropriate decision-making, and seeking information and support. These positive confrontations are considered as evidence of an individual's health, harmony, and quality of life [12].

Gifted students have high mental abilities and follow their desired academic and professional interests. Although they are actively involved in many activities and are able to succeed in several areas, they may face difficult to make a professional decision, especially when there are numerous career options. Some call it an "over choice syndrome" and when adolescents are associated with critical dimensions in the educational and vocational aspects, individual differences are significant in both areas through using educational and professional assessment scales.

\subsection{Career Decision-Making Difficulties}

Career decision-making difficulties indicated that an individual is incapable of making a particular career decision at a specific time. Specifically, career decision-making difficulties refer to difficulties in making the final decision in the career choice process (entry phase or career change). From the study of personality regarding career decision-making, there is a significant body of research examining decisional styles, processes, and strategies related to career decision problems. Three decision-making styles have been identified: rational, avoidant, and dependent. The rational style is an active and planned approach to decision making. The avoidant style is characterized by failure to attain and process career information, and the procrastination of decisions. The dependent style involves ceding responsibility for decisions to external sources, such as significant others. The rational style is favored because it is a systematic approach that yields information relevant to decisions [23]. Gati et al. [6] suggested using the profiles of 11 different decision dimensions. Information gathering reflects the degree of involvement in the collection and organization of information. Information processing refers to the extent of career information analyses. Locus of control is the degree of one's perceived control over career opportunities. Effort invested in the process reflects the time and effort devoted to career decision-making. Procrastination is the delay in involvement in decision-making tasks. The speed of making the final decision reflects the time needed to finalize career decision.

\subsection{Psychological Resilience}

Psychological resilience is defined as "an ability that enables an individual to confront positively or adapt to the threats, pitfalls and calamities he is exposed to in his life, and to achieve positive life outcomes" It also indicated the positive compatibility of coping with adversity. It is a broad concept that includes the response system competence and psychological resilience in coping with challenges [21]. Studies on psychological resilience have examined at-risk populations to understand the factors 
impacting students' life decisions and their developmental pathways because psychological resilience is both individually and culture specific. It may be considered as risk factor for one individual may not be for another with a different predisposition in terms of characteristics and environment, For example, a grade of a $\mathrm{C}$ grade on a test may be viewed as success by one individual and failure by another, depending on their situations [15]. The intellectual development of the gifted contributes to limiting the appearance of side effects of social problems, and high cognitive skills seem to constitute a psychological force for psychological resilience, because they provide problem's solving when facing difficult situations. A study by Lopez and Sotillo [14] supported the idea that being gifted acts as a preventive agent that helps students to be more confident about themselves than the non-gifted. Their mental abilities often demonstrate that they are more mature, positive, and responsible. They understand themselves, and possess an internal control orientation when facing risks, that exhibits an academic resilience, regardless of the risk factors. Shin and Kelly [23]. suggested that there is a relationship between psychological resilience and the ability to resolve career decision problems for two reasons. First, career decision making is a normative task during late adolescence, and psychological resilience is related to adaptive functioning. Resilient adolescents develop strategies and coping skills to adapt to stressors, including career indecision, and attain positive outcomes. Second, psychological resilience is related to adaptive functioning in work environments. For example, resilient employees in a call centre relied more on their personal abilities and less on external support when responding to challenges. Therefore, psychological resilience is positively related to the ability to resolve career decision problems.

\section{Materials and Methods}

\subsection{Research Sample}

The original sample consists of 1200 students form 30 public secondary schools, 14 for males and 16 for females, among them (422) are gifted. Students are diagnosed according to criteria determined by the National Center for Assessment. Among those criteria: (1) Nomination through behavioral characteristics scale. (2) Obtaining a percentile score that within the top $5 \%$ of the standardized capacity test for the Saudi environment. Students receive enrichment services through pull out from the regular class for some time to study enrichment topics of a higher level than what the regular curriculum provides. This research was performed with (80) gifted students by purposive selected in the secondary stage in Al-Ahsa city, Saudi Arabia. The sample comprised (40) males and (40) females, aged 15-19 years, with mean of 17.8 and a standard deviation of 1.23 . These students had been enrolled in gifted programs.

\subsection{Research Instrument}

\subsubsection{Coping Strategies for Difficulties in Career Decision-Making (CDCDM)}

This scale was developed by the researcher and intended for secondary school students. The scale aims to evaluate coping strategies for difficulties in career decision-making. The form of the scale consists of 70 items and 12 subscales: planning, information processing, consulting with others, soft skills, locus of control, vigilance impulsiveness, intuition dependence on others, procrastination, withdrawal and indecisiveness. The external criterion validity was calculated for the scores of the strategies scale for decision-making difficulties, prepared by the researcher, and the scores of the decision-making difficulties scale by Gati [6] on a sample of 50 students. Based on the results, the correlation coefficient value was found to be 0.86 and the test-retest reliability after two weeks was found to be $0.79(\mathrm{p}<.01)$ which is statistically significant.

\subsubsection{Career Decision- Making Difficulties Questionnaire (CDDQ)}

The researcher Translated the original version of the CDDQ Gati \& Saka, [4]. It is a 25 item questionnaire designed to measure the career decision difficulties through seven subscales lack of information, non-functional beliefs, lack of information on jobs, frequency of general external conflicts, lack of information about the process and procedures, and lack of motivation. The scale has shown high reliability across many samples from Europe, America, China, Japan and Greece. The reliability of the scale was calculated using the Alpha coefficient and ranged between $0.59-0.86$. The matrix of correlation coefficients between the scale's degree ranged between $0.21-0.93$. The overall score was 0.88 , indicating the validity and reliability of the scale were accepted.

\subsubsection{Psychological Resilience Scale (PRS)}

This scale was developed by the researcher to measure the psychological resilience in gifted adolescents, the scale consists of 50 items and seven subscales: novelty seeking, emotional regulation, positive future orientation, spiritual competence, personal competence, social competence and self-acceptance. The external criterion validity was calculated for the scores of the psychological resilience scale for gifted adolescents and psychological resilience scale prepared by Hjmedal [8]. On a sample of 40 students, The correlation coefficient value was 0.82 , statistically significant at the 0.01 level. The test-retest reliability after two weeks was 0.79 which is statistically significant. The self-report scale had the options "always, 
sometimes, and never" and the degrees "3, 2, and 1" for the positive item, and vice versa for the negative items.

\section{Results}

Data analysis was conducted to determine the relationship between strategies of career decision making, psychological resilience and career decision-making difficulties, as presented in:

Table.1: To see the relationship between coping strategies of career decision-making difficulties, and degrees of career decision-making difficulties, and psychological resilience the researcher used Person's simple correlation test. The results showed that Person's simple correlation coefficient is 0.679 , which shows the direction of a positive relationship between coping strategies of career decision-making difficulties and psychological resilience. In addition, the results showed a statistically significant correlation is 0.631 between coping strategies of career decision-making difficulties, and career decision-making difficulties in total degrees.

Table 1. Correlations between coping strategies of career decision making, psychological resilience, and career decision-making difficulties

\begin{tabular}{|c|c|c|}
\hline Coping strategies of career decision-making & $\mathrm{R}$ & Sig. \\
\hline psychological resilience & 0.679 &.$* *$ \\
\hline Career decision-making difficulties & 0.631 &.$^{* *}$ \\
\hline
\end{tabular}

Table 2. Mean, standard deviation and T- test on dimensions of strategies of career decision-making between males and females

\begin{tabular}{|c|c|c|c|c|c|c|}
\hline & \multicolumn{2}{|c|}{ Males } & \multicolumn{2}{c|}{ Females } & \multirow{2}{*}{ T } & Sig. \\
\hline Planning & 12.82 & 1.58 & 13.17 & 1.50 & 1.015 & - \\
\hline $\begin{array}{c}\text { Information } \\
\text { analysis }\end{array}$ & 14.97 & 1.12 & 14.70 & 1.13 & 1.090 & - \\
\hline $\begin{array}{c}\text { Consulting } \\
\text { with others }\end{array}$ & 16.07 & 2.33 & 15.37 & 1.77 & 1.508 & - \\
\hline Soft skills & 15.02 & 1.47 & 14.57 & 1.41 & 1.368 & - \\
\hline $\begin{array}{c}\text { Locus of } \\
\text { control }\end{array}$ & 13.32 & 1.28 & 12.07 & 1.44 & 1.878 & - \\
\hline Vigilance & 14.45 & 1.46 & 13.30 & 1.43 & 3.544 &.$^{* *}$ \\
\hline Impulsiveness & 13.82 & 0.93 & 12.65 & 1.51 & 4.187 & $* * *$ \\
\hline Intuition & 13.92 & 1.65 & 14.35 & 1.33 & 1.266 & - \\
\hline $\begin{array}{c}\text { Dependence on } \\
\text { others }\end{array}$ & 12.42 & 1.41 & 13.66 & 1.00 & 4.475 & $* * *$ \\
\hline Procrastination & 13.37 & 0.978 & 12.25 & 1.12 & 4.767 & $* * *$ \\
\hline Withdrawal & 12.82 & 1.58 & 14.25 & 1.29 & 4.405 &.$^{* *}$ \\
\hline Indecisiveness & 14.32 & 1.38 & 15.82 & 1.81 & 4.163 & $*^{* *}$ \\
\hline
\end{tabular}

Table 2. Mean and standard deviation and T- test on dimensions of coping strategies of career decision-making difficulties between males and females. There is a statistically significant difference at 0.01 level between males and females in dimensions of vigilance, impulsivity, and procrastination were in favour of males. Where the dimensions of dependence on others, withdrawal, and indecisiveness were in favour of females. However, there were no differences between them in strategies such as: planning, information analyses, consulting with others, soft skills, locus of control, and intuition.

Table 3. Mean, standard deviation and $\mathrm{T}$ - test on psychological resilience between males and females. The results showed that there is a statistically significant difference a 0.01 level between males and females in psychological resilience, in favour of males in total degree.

Table 3. Mean, standard deviation and T- test on resilience between males and females

\begin{tabular}{|c|c|c|c|c|c|c|}
\hline \multirow{2}{*}{ Dimensions } & \multicolumn{2}{|c|}{ Males } & \multicolumn{2}{c|}{ Females } & \multirow{2}{*}{$\mathrm{T}$} & \multirow{2}{*}{ Sig. } \\
\cline { 2 - 5 } & $\mathrm{M}$ & $\mathrm{SD}$ & $\mathrm{M}$ & $\mathrm{SD}$ & & \\
\hline Resilience & 91.62 & 3.90 & 88.92 & 2.35 & 3.742 & $* *$ \\
\hline
\end{tabular}

Note. ${ }^{*} \mathrm{p}<0.05$. $* * \mathrm{p}<0.01$.

\section{Discussion}

Career decision-making depends on a set of strategies related to the psychological, cognitive, motivational and behavioral aspects. Psychological resilience plays a vital role in successful decision-making based on problem-based strategies. Decision-making is one of the main method of confronting a problem or a situation, It activate psychological resilience during confrontation pressures of the problem, and helps strengthen this relationship on several dimensions, including the concept of self, perfectionism, locus of control, level of aspiration, search for status, planning and information collection and analysis. It helps weakens dimensions such as withdrawal, extreme care, poor self-confidence, indecision, and procrastination.

Individuals with psychological resilience have a tendency toward optimism and participation in life, characterized by their ability to link and commit active behaviour and problem-based confrontation in response to challenges or disappointing situations. It is not surprising that psychological resilience is associated with career decision-making, and success in overcoming the difficulties of career decision-making. Procrastination is a strategy linked to three decision-making difficulties, namely, lack of readiness, lack of information, and inconsistent information. Results also point to the importance of reducing procrastination at all stages of decision-making and the need to promote psychological resilience to deal with decision difficulties [23].

Good decision-making plays an important role in emotional cognitive and social factors, due to its functional role in emotional organization, self-management, training in critical thinking, and confidence in future decision-making. Participation in decision-making helpful in the growth of self-esteem, 
cognitive abilities, social skills, and respect for others. It also increases mastery and control, relieves stress and anxiety, promotes a sense of belonging and a sense of value, the growth of social skills and self-esteem, and psychological resilience. In contrast, there is lack of participation in decision-making affects on mental health negatively.

Previous studies (e.g. Shin and Kelly, [23] Jung, [9]. indicated that career decision-making strategies are statistically significant on career decision-making difficulties in general. In particular, it was found that the locus of control, procrastination, and dependence on others, and the desire to satisfy others was associated with decision-making difficulties in some strategies. Gati et al. [7] found that willingness to compromise is essential when implementing choices. However, the current finding suggested that it may not be helpful during the information-gathering process. they tentatively concluded that aspirations for an ideal choice should be assessed for students who are yet begin the career-search process. Excessive willingness to compromise should be considered by the counsellors as a potential inhibitor of the information-gathering process.

Procrastination strongly signals the participation delay in information gathering; a growing awareness of the difficulties of decision-making and addressing the views of others is linked to decision-making difficulties. Individuals with internal control have a negative correlation with dependence on others and a desire to please them; therefore, they are less likely to delay the information collection and analysis and to have difficulties in decision-making in general. The preference for quick decisions (impulsivity) is negatively associated with the lack of willingness to work, dependence on others, and the desire to please them. Aspiration for an ideal workplace is positively associated with the lack of willingness to make decisions. one of the most issues that should be addressed was procrastination. Access to the sources of information about available occupations is positively correlated with the willingness to compromise and make decisions. Many inconsistency problems can be resolved by simply gathering more information. The positive relationship between desire to please others and inconsistent information may be more difficult to address in counselling. Factual discrepancies are relatively easy to address. Value or opinion discrepancies between the decision maker and their significant others may be more difficult to resolve [23]. It was concluded that strategies to face the career decision-making difficulties are both positive and negative with the decision-making difficulties in the study sample. Negative strategies negatively affect the ability to make decision; in contrast, positive strategies help students to make career decisions correctly.

Previous studies indicated that gender have a significance influence on decision-making. Gender differences have been found in relation to the area of interest and commitment to relevance, academic and professional ambition levels, and social role. Although gifted students generally show real interests, there are wide differences between them. According to Ogurlu [17] found that males have a higher vocational aspiration, prestige, academic achievement, and commit themselves to careers that require physical effort. However, females' express of interests in a wide range of professions that contribute to the attitudes of both the sexes; they want more prestige and tend to exhibit high levels of personality traits. It is concluded that the differences in some strategies in favor of males such as vigilance, impulsive and procrastination, are related to their biological nature, opportunities for experimentation and excessive enthusiasm for discovery. However, differences in the strategies in favor of females, such as dependence on others, withdrawal, and frequency is predominantly related to the nature of females. Being careful asking others for help, and fear of experimenting also, show that there are no differences between males and females in strategies such as: planning, information processing, consultation with others, the acquisition of soft skills, locus of control, and intuition, because they are distinguished the ability to employ knowledge and information and the acquisition of soft skills that distinguish them from others, and they are involved together in the possession of those strategies and the application, because of educational and professional ambition, and females are different from males due to the impact of external, such as factors: peer, family, teachers pressure and social environment. Strategies to address the decision-making difficulties, helps students to cope with these difficulties and is linked to their quality of psychological resilience.

The results of some previous studies indicated that there are no differences in psychological resilience among gifted males and females (e.g. Lopez\&Sotello [16]. Mohammadi [14]. However, in the comparison between the ordinary and the gifted, the differences are in favour of the latter. In the current study, the dimensions of the psychological resilience scale were personal competence, social competence, novelty seeking, positive orientation toward the future, self-acceptance, and spiritual competence. Males were higher than females in some dimensions because their nature of males and the opportunities for personal interaction, acquiring social skills, and achieve self-acceptance. Resistance is linked to the ability to adapt in work environments, and it is inversely related to stress, and positively related to the ability to resolve various occupational decisions. The relationship between psychological resilience and career decisions making difficulties enable professional counsellors to develop and design interventions that build psychological capital (self-efficacy, optimism, and hope). Psychological resilience helps individuals cope with stressful situations, by developing positive methods such 
as: problem-solving ability, positive problem interpretation, and resorting to religious and spiritual values to reduce stress and despair.

The results of some studies indicated that the gifted students' resilience increases with age, and that there is a relationship between psychological resilience, self-confidence, and internal courage. Resilience is an important factor that could distinguish between the gifted students who were able to achieve and those who could not. Moreover, cognitive abilities, such as problem-solving and coping, were found to be a significant factor in the development of gifted students' resilience [1]. The differences are due to socialization and restrictions on females, differences between aspirations, academic success and career choices, as well as cultural and social considerations that may outweigh desires and concerns. Therefore, vocational guidance is needed to promote female empowerment and to change gender stereotypes and roles.

\section{Conclusions}

The results of this research showed that there is statistically significant correlation between coping strategies of career decision making difficulties, decision making difficulties, and psychological resilience with gifted. In addition, there is significant differences in coping strategies of career decision making in subscales: dependence on others, withdrawal, and indecisiveness in favor of the females, and vigilance, impulsiveness, procrastination in favor of males. As well, there is significant differences in psychological resilience in favor of the males. The career decision-making process for gifted students can be more than just a step in the process of completing postsecondary school. They need to acquire many of the coping strategies of decision-making difficulties, and psychological resilience is a very important factor in achieving this. They need targeted support from adults, including teachers, parents, and counsellors. Counsellors can work together with students to help them to construct their own path in order to success and confidently move into postsecondary and professional worlds.

\section{Recommendations}

In light of the findings, the research recommend for conducting more training and counselling programs to enhance coping strategies of career decision making difficulties. In light of variables that are not addressed in the current study, such as perfectionism, self- efficacy, life satisfaction, and social adjustment, there also should be experimental studies that aims to design counselling programs to improve coping strategies, and psychological resilience, for reducing career-decision- making difficulties. Psychological and professional counselors should prepare training programs on how to make the appropriate career decision-making, and face the difficulties of making it, such as: procrastination, withdrawal, and indecisiveness, and impulsivity, with effective ways and positive strategies.

\section{Acknowledgements}

The author acknowledges the deanship of scientific research at King Faisal University, to receive financial support for the research, authorship, and publication of research n. (186321).

\section{REFERENCES}

[1] Chen, X., Hoi Yan., Xitao, F. \& Joseph, W. (2017). Factors related to resilience of academically gifted students in the Chinese cultural and educational environment. Wiley, Psychol Schs, 55,107-119. https://doi.org/10.1002/pits.220 44

[2] Chen, C. \& Joyce, W. (2013). Career counseling for gifted students. Australian Journal of Career Development,22 (3),121-129. DOI: 10.1177/1038416213507909

[3] El Khoury, Sara, Al-Hroub, Anies (2018). Gifted Education in Lebanese Schools Integrating Theory, Research, and Practice. SpringerBriefs in Psychology, https://doi.org/10.1007/978-3-319-78592-9_2

[4] Frydenberg, E. (2017). Coping and the challenge of resilience. Palgrave Machmillan, London. DOI 10.1057/978-1-137-56924-0_1

[5] Gati, I., \& Saka, N. (2001). Internet-based versus paper-and-pencil assessment: Measuring career decision-making difficulties. Journal of Career Assessment, 9, 397-416.

[6] Gati, I., Landman, S., Davidovitch, S., Asulin-Peretz, L., \& Gadassi, R. (2010). From career decision-making styles to career decision-making profiles: A multidimensional approach. Journal of Vocational Behavior, 76, 277-291. DOI:10.1016/j.jvb.2009.11.001

[7] Gati, I., Gadassi, R. \& Mashiah, R. (2012). Career decision-making profiles vs. styles: Convergent and incremental validity. Journal of Vocational Behavior, 81, 2 16. DOI:10.1016/j.jvb.2012.03.004

[8] Hjemdal, O., Friborg. O, Stiles, J. (2006). A new scale for adolescent's resilience: Grasping the central protective resources behind healthy development.

[9] Jung Jae,. Y. (2018). The career decision of gifted students and other high ability groups. Rotledge.

[10] Kurt J. Layla (2016). Career Counseling for Gifted Students: Understanding Student Needs and Strategies for Success. The Practitioner Scholar: The Journal of Counseling and 
Professional Psychology, 5, 156-168.

[11] Lipshits Y., Gati,I., Tatar,M. (2015a). Strategies for coping with career indecision. Journal of career assessment, 1-25. DOI: $10.1177 / 1069072714566795$

[12] Lipshits, Y., Gati,. Tatar, M. (2015b). Strategies for coping with career indecision: convergent, divergent, and incremental validity. Journal of career assessment, 25 (2), 183-202. DOI: $10.1177 / 1069072715620608$

[13] Lipshits, B, Y., Bercovitz, H., \& Royf, N. (2018). Strategies for coping with career indecision during the college-to-work transition: Concurrent and predictive validity. Journal of Career Assessment, 2 (1), 1-17. https://doi.org/10.1177/106 9072718759983

[14] Lopez, V.\& Sotillo, M. (2009). Giftedness and social adjustment: Evidence supporting the resilience approach in Spanish-speaking children and adolescents. High Ability Studies, 20, 39-53.

[15] Mihyeon, K. (2015). Enhancing resilience of gifted students. Texas association for the gifted \&gifted. Tempo, 15 (3),17-21. https://scholarworks.wm.edu/articles/71

[16] Mohammadi, M., Akram, S., Abolfazl. K., \& Ali, K. (2018). Association of parenting style with self-efficacy and resilience of gifted and ordinary male high school students in Sari, Iran. Journal Clinical and Basic Research, 2(3), 25-32. DOI: $10.29252 /$ jcbr.2.3.25
[17] Ogurlu, U.,Faith, K. \& Emine, H. (2015). Career decision of gifted students in Turkey. Journal of European Education, 5 (1), 31-45. DOI:10.18656/JEE.86698

[18] Ozcan, D. \& Zaaroglu, L. (2017). Determination of the relationship between strategies of decision-making and emotional intelligence of gifted students. ENSAYOS. Revista de la Facultad de Educación de Albacete, 32 (2), 77-95. http://www.revista.uclm.es/index.php/ensayos

[19] Pellerone, M. (2013). Identity status, coping strategies and decision-making process among Italian University students. Procedia, Social and Behavioral Science, 106, 1399-1408. https://doi.org/10.1016/j.sbspro.2013.12.156

[20] Piers Lisa (2015). Fostering resilience with students with learning disabilities: An ecological approach. Faculty of Education University of Ottawa, Canada.

[21] Shane,S. \& Lopez, J. (2013). The encyclopedia of positive psychology. Wiley- Blackwell.

[22] Seward, K. \& Goesser, A. (2018). Career decision making with gifted rural students. Gifted child today, 41 (4), 217-225. https://doi.org/10.1177/1076217518786986

[23] Shin,Yun-J. \&Kelly, R. (2015). Resilience and decision making strategies as predictors of career decision difficulties. The Career Development Quarterly, 63,291-305. DOI: 10.1002/cdq. 12029 